In Studies in Surface Science and Catalysis 143, Scientific Basis for the Preparation of Heterogeneous Catalysts, Eds. E. Gaignaux, D. E. De Vos, P. Grange, P. A. Jacobs, J. A. Martens, P. Ruiz and G. Poncelet, Proceedings of the $8^{\text {th }}$ International Symposium 'Scientific Basis for the Preparation of Heterogeneous Catalysts', $\begin{array}{llll}\text { Louvain-la-Neuve, } & 9-12 \quad \text { September } & \text { 2002, } & \text { p. }\end{array}$ 


\title{
Catalytic Activity of Bulk and Supported Sulfated Zirconia
}

\author{
Ivo J. Dijs, Leonardus W. Jenneskens, and John W. Geus \\ Debye Institute, Department of Physical Organic Chemistry, \\ Utrecht University, Padualaan 8, 3584 CH Utrecht, The Netherlands
}

\begin{abstract}
Summary
To assess whether Lewis acid sites are present on zirconium sulfate, we prepared water-free bulk zirconium sulfate. Furthermore, a water-free silica-supported zirconium sulfate catalyst was prepared by deposition-precipitation of zirconia on silica and subsequent gas-phase reaction with $\mathrm{SO}_{3}$. The activity of these catalysts was compared with that of two conventionally prepared sulfated zirconia catalysts.

The different catalysts were extensively characterized. XPS indicated that the conventionally prepared sulfated zirconia catalysts contained sulfuric acid. The activity of the catalysts was determined with the gas-phase trans-alkylation of diethylbenzene with benzene and the solvent-free liquid-phase addition of acetic acid to camphene.

Both water-free zirconium sulfate catalysts did not exhibit a significant activity; Lewis acid sites are therefore not active in these sulfated zirconia catalysts. Upon exposure to water vapor the initially water-free catalysts were active. The stability of the conventional sulfated zirconia catalysts appeared to be determined in the gas-phase by the volatilization of sulfuric acid. As a result, a highly porous catalyst was more effective than a catalyst based on zirconia of a relatively low porosity. With liquidphase reactions extraction of sulfuric acid proceeds leading to an acid liquid, which is catalytically active also after separation of the solid catalyst from the reaction mixture.
\end{abstract}

\section{Introduction}

The presence of catalytically active Lewis acid sites in sulfated zirconia catalysts is much debated [1-5]. The conventional preparation of sulfated zirconia catalysts involves reaction of freshly precipitated zirconium hydroxide with diluted sulfuric acid or impregnation of zirconium hydroxide with sulfuric acid or ammonium sulfate [6,7]. The final solid acid catalyst results by calcination at a temperature of 723 to $873 \mathrm{~K}$. Provided thermodynamic equilibrium has been reached, all water and free sulfuric acid should have evaporated upon calcination at 673 to $873 \mathrm{~K}$ and only chemically bonded sulfate groups remain [8]. Above 890 $\mathrm{K}$, bulk anhydrous $\mathrm{Zr}\left(\mathrm{SO}_{4}\right)_{2}$ decomposes [1]. When uptake of water by the calcined catalyst is prevented or after loading of the catalyst in the reactor physisorbed water is removed by thermal treatment, only Lewis acid sites are present. Since it is difficult either to prevent the uptake of water vapor or to remove adsorbed water completely, it is difficult to attribute the acid activity of sulfated zirconia catalysts unambiguously to Lewis acid sites.

In view of the fact that complete removal of water vapor cannot be readily achieved, we prepared water-free bulk and silica-supported zirconium sulfate. The bulk anhydrous $\mathrm{Zr}\left(\mathrm{SO}_{4}\right)_{2}$ was obtained by reaction of zirconium tetrachloride with oleum [1]. The silica-supported zirconium sulfate resulted from deposition-precipitation of zirconium hydroxide on silica, calcination at $723 \mathrm{~K}$ and subsequent reaction with gaseous sulfur trioxide. The catalytic activity of the sulfated zirconia's was measured in the gas-phase trans-alkylation of benzene (1) with diethylbenzene (2) to ethylbenzene (3, reaction 1) [8,9] and the liquid-phase hydroacyloxy-addition reaction of acetic acid (4) and camphene (5) to isobornyl acetate $(\mathbf{6}$, reaction 2) $[8,10]$. With the trans-alkylation we used an amorphous silica-alumina catalyst as a reference.

For comparison purposes we prepared and investigated also two different sulfated zirconia catalysts prepared conventionally [6,7]. One catalyst was prepared by reaction of $0.5 \mathrm{M}$ $\mathrm{H}_{2} \mathrm{SO}_{4}$ with freshly precipitated zirconium hydroxide and calcination at $773 \mathrm{~K}$ $\left[\mathrm{H}_{2} \mathrm{SO}_{4} / \mathrm{ZrO}_{2}\right.$ (prec.) $]$, the other in a similar way but with calcined zirconia $\left[\mathrm{H}_{2} \mathrm{SO}_{4} / \mathrm{ZrO}_{2}(\mathrm{Gimex})\right]$ [8]. It is interesting that it has been concluded from their infrared spectra that addition of water vapor leads to formation of sulfuric acid [5]. As the volatility of sulfuric acid and its constituents is higher than that of metal sulfates, the transport of water and sulfur oxides out of the porous structure of the zirconia is important. 


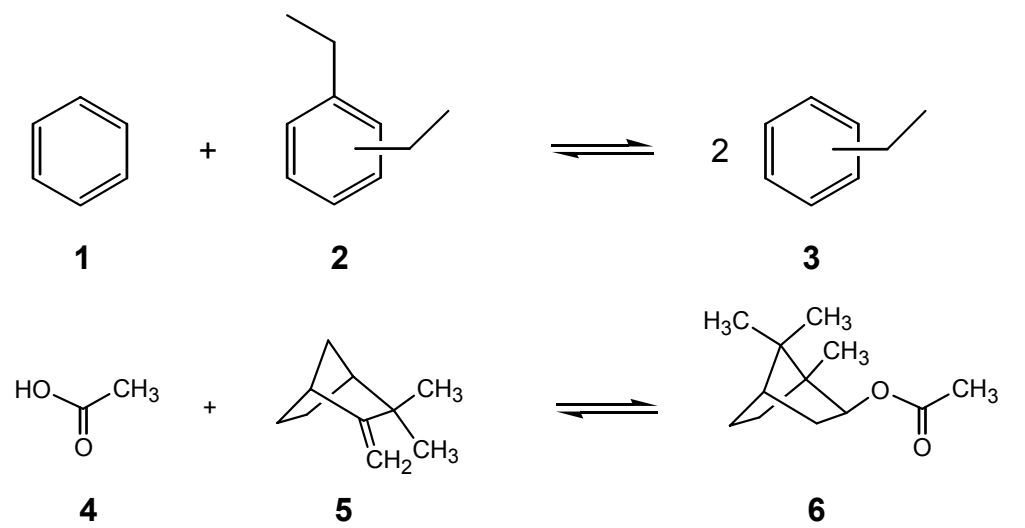

The difficult transport of strongly adsorbing molecules out of a porous system may give an explanation for the result mentioned in the literature that the reaction of zirconium hydroxide with sulfuric acid leads to a fairly active catalyst, whereas reaction of calcined zirconia with sulfuric acid providing the same sulfur content did not result in an active catalyst [11]. Accordingly, the removal of the constituents of sulfuric acid out of calcined zirconia will proceed much more smoothly than that out of zirconium hydroxide. The activity of catalysts prepared from zirconium hydroxide thus may be due to water and sulfuric acid remaining in the catalyst providing Brønsted acid sites. The sulfated zirconia catalyst based on non-porous calcinied zirconia $\left[\mathrm{H}_{2} \mathrm{SO}_{4} / \mathrm{ZrO}_{2}(\right.$ Gimex $\left.)\right]$, on the other hand, will loose readily most of its sulfuric acid during thermal treatment.

Furthermore, we investigated the effect of water on the activity of the above-mentioned sulfated zirconia catalysts and the observed activities were compared. We have extensively characterized the different catalysts by XPS, physical adsorption, analytical electron microscopy, and thermogravimetry.

\section{Experimental}

\subsection{Catalyst preparation}

The water-free bulk zirconium sulfate $\mathrm{Zr}\left(\mathrm{SO}_{4}\right)_{2}$ was prepared by treatment of $\mathrm{ZrCl}_{4}$ with oleum as published earlier [1].

The preparation of the silica-supported, water-free sulfated zirconia catalyst started with the deposition-precipitation of zirconia on silica. In a reaction vessel $(2 \mathrm{~L})$ equipped with a pH-meter, thermometer, baffles and a stirrer $(1000 \mathrm{rpm}), 13.5 \mathrm{~g}(0.225 \mathrm{~mol}) \mathrm{SiO}_{2}$ [Aerosil OX50 (Degussa-Hüls), $50 \mathrm{~m}^{2} / \mathrm{g}$ ] was suspended in $750 \mathrm{~mL}$ water. Under stirring, both $4.0 \mathrm{M}$ $\mathrm{HCl}$ and $4.0 \mathrm{M} \mathrm{NH}_{3}$ were separately injected via narrow tubes (i.d. $1.0 \mathrm{~mm}$ ) ending below the level of the liquid using two Gilson Minipuls III peristaltic pumps. Whereas the $4.0 \mathrm{M} \mathrm{HCl}$ was injected at $0.25 \mathrm{~mL} / \mathrm{min}$, the injection of the $4.0 \mathrm{M} \mathrm{NH}_{3}$ solution was automatically regulated to maintain a $\mathrm{pH}$ of 4.5 . When a constant $\mathrm{pH}$ of 4.5 was reached, the $4.0 \mathrm{M} \mathrm{HCl}$ was replaced by a $4.0 \mathrm{M} \mathrm{HCl}(250 \mathrm{~mL})$ solution containing $3.92 \mathrm{~g}(12.2 \mathrm{mmol}) \mathrm{ZrOCl}_{2} .8 \mathrm{H}_{2} \mathrm{O}$. After addition of these solutions at a $\mathrm{pH}$ of 4.5 , the $\mathrm{pH}$ was raised to 6.5 with the $4.0 \mathrm{M} \mathrm{NH}_{3}$ solution. The wet residue was re-suspended three times in water $(300 \mathrm{~mL})$ for one day followed by filtration in order to remove remaining $\mathrm{NH}_{4} \mathrm{Cl}$ impurities. The final residue was dried at $393 \mathrm{~K}$ for one day and subsequently sieved; the 500-850 $\mu \mathrm{m}$ fraction was isolated. Calcination was performed under carefully controlled conditions using a quartz fixed bed reactor (i.d. $10 \mathrm{~mm}$ ) equipped with a K-type thermocouple. The 500-850 $\mu \mathrm{m}$ sieve fraction was calcined at $723 \mathrm{~K}$ for $10 \mathrm{~h}$ (heating/cooling rate: $5 \mathrm{~K} / \mathrm{min}$ ) in a dry air flow $(50 \mathrm{~mL} / \mathrm{min}$ ). On top of the sieve fraction, glass beads $(\mathrm{d} 1.0 \mathrm{~mm})$ were placed to achieve effective preheating of the air.

The next step involved the sulfation of the small zirconia particles. For the oxidation of $\mathrm{SO}_{2}$ to $\mathrm{SO}_{3}$ a layer of a finely powdered $2 \mathrm{wt} \% \mathrm{Pt} / \mathrm{SiO}_{2}$ catalyst was installed at half-height of the glass bead layer. Helium was used to maintain a gas flow of $50 \mathrm{~mL} / \mathrm{min}$. The temperature 
was raised to $675 \mathrm{~K}$ at $5 \mathrm{~K} / \mathrm{min}$. Subsequently 5 vol.\% of $\mathrm{SO}_{2}$ and 5 vol. $\%$ of $\mathrm{O}_{2}$ were added to the helium flow, which was maintained for $5.5 \mathrm{~h}$. Via a heat-traced tube $(423 \mathrm{~K})$ the gasflow leaving the reactor was passed through a stirred suspension of $\mathrm{Ca}(\mathrm{OH})_{2}$ in water. Next, the temperature was lowered to $573 \mathrm{~K}$ and the $\mathrm{SO}_{2}$ and $\mathrm{O}_{2}$ were switched off, after which the temperature was decreased to room temperature at $5 \mathrm{~K} / \mathrm{min}$.

A literature procedure was used for the preparation of calcined $\mathrm{H}_{2} \mathrm{SO}_{4}$-impregnated $\mathrm{ZrO}_{2}$ catalysts [6,7]. Two different $\mathrm{ZrO}_{2}$ sources were used.

(1) Precipitated $\mathrm{ZrO}_{2}: 20.23 \mathrm{~g}(62.8 \mathrm{mmol}) \mathrm{ZrOCl}_{2} .8 \mathrm{H}_{2} \mathrm{O}$ was dissolved in water $(160 \mathrm{~mL})$ and $25 \mathrm{wt} \% \mathrm{NH}_{3}$ was added dropwise under vigorous stirring until $\mathrm{pH}=8$. Next, the $\mathrm{NH}_{4} \mathrm{Cl}$ was removed re-suspending the wet residue by four times in water $(300 \mathrm{~mL})$ for one day followed by filtration. The $\mathrm{ZrO}_{2}$ residue was dried at $433 \mathrm{~K}$ for $16 \mathrm{~h}$.

(2) Commercial $\mathrm{ZrO}_{2}$ (Gimex B.V., The Netherlands, surface area $60 \mathrm{~m}^{2} / \mathrm{g}$, monoclinic).

Sulfation of both zirconia's was performed by stirring $4.0 \mathrm{~g}(32.46 \mathrm{mmol})$ of each zirconia sample with $20 \mathrm{~mL} 0.5 \mathrm{M} \mathrm{H}_{2} \mathrm{SO}_{4}$ for $3 \mathrm{~h}$ and drying at $433 \mathrm{~K}$ for $16 \mathrm{~h}$ (no filtration). Sieve fractions $(500-850 \mu \mathrm{m})$ were calcined in a flow of dry air $(50 \mathrm{~mL} / \mathrm{min})$ at $773 \mathrm{~K}$ for $3 \mathrm{~h}$ (heating/cooling rate: $10 \mathrm{~K} / \mathrm{min}$ ). The catalysts were isolated from the reactor as well as stored under dry air prior to analysis and application.

\subsection{Catalyst characterization}

XPS analysis was performed on a Vacuum Generators (Fisons Instruments) MT-500 with a non-monochromatic Al X-ray source (Ka $1486.6 \mathrm{keV})$ and a CLAM-2 hemispherical analyzer for electron detection. The samples were supported on carbon adhesive tape. Spectra were corrected for charging using the $\operatorname{Si}(2 p)$ peak and scaled on the $\operatorname{Si}(2 s)$ peak. For the determination of the binding energies a background correction was applied.

Thermostabilities were determined by analyzing the relative loss of weight in a dry $\mathrm{N}_{2}$ flow $(50 \mathrm{~mL} / \mathrm{min})$ as a function of temperature and time with a PC-controlled Perkin-Elmer TGS-2 TGA apparatus, autobalance AR-2. Temperature program: $1 \mathrm{~h}$ at $323 \mathrm{~K}$, heating rate $10 \mathrm{~K} / \mathrm{min}$ to $1123 \mathrm{~K}$ followed by $15 \mathrm{~min}$ at $1123 \mathrm{~K}$. Samples of $c a .3 .5 \mathrm{mg}$ were used.

Transmission electron microscopy was performed with a Philips EM420 and a Philips CM200 equipped with a field-emission gun and an EDAX detector for elemental analysis. Ground and ultrasonically dispersed (in dry $n$-hexane) samples were brought on copper grids covered by a thin polymer film on which carbon was deposited.

SEM analysis was performed with a Philips XL 30 FEG equipped with an EDAX detector for elemental analysis. The samples were supported on carbon adhesive tape and covered with a carbon layer by vapor-deposition.

\subsection{Gas-phase trans-alkylation of benzene (1) and diethylbenzene(2)}

The gas-phase trans-alkylation reaction was performed in an automated micro-flow apparatus containing a quartz fixed-bed reactor (i.d. $10 \mathrm{~mm}$ ) at $10^{5} \mathrm{~Pa}[16 \mathrm{vol} \%$ benzene $(\mathbf{1}$, p.a., dried on molsieve), 3.2 vol\% diethylbenzene (2, consisting of $25 \%$ ortho, $73 \%$ meta, $2 \%$ para isomers, dried on molsieve), $\mathrm{N}_{2}$ balance $(50 \mathrm{~mL} / \mathrm{min})$, WHSV $=1.5 \mathrm{~h}^{-1}$ ] with $2.0 \mathrm{~mL}$ of the tube reactor filled with catalyst particles $(500-850 \mu \mathrm{m}$ sieve fraction, typically $1.4 \mathrm{~g})$. Two separate saturators were connected to the inlet of the reactor for the supply of $\mathbf{1}$ and $\mathbf{2}$. The partial vapor pressure of $\mathbf{1}$ and $\mathbf{2}$ was controlled by adjusting the temperature of the saturatorcondensers and the $\mathrm{N}_{2}$ flow rate. After equilibration for $30 \mathrm{~min}$ at the applied reaction temperatures $(473 \mathrm{~K}$ and $673 \mathrm{~K}$, heating rate $10 \mathrm{~K} / \mathrm{min})$ within a dry $\mathrm{N}_{2}$ flow $(50 \mathrm{~mL} / \mathrm{min})$, benzene (1) and diethylbenzene (2) were passed through the reactor. To prevent condensation of both reactants and products prior to GC analysis [Hewlet Packard $5710 \mathrm{~A}$, column: CP-sil 5CB capillary liquid-phase siloxane polymer $(100 \%$ methyl $) 25 \mathrm{~m} \times 0.25 \mathrm{~mm}, 323 \mathrm{~K}$, carrier gas: $\mathrm{N}_{2}$, FID, sample-loop volume: $1.01 \mu \mathrm{L}$ ], tubes were heat-traced (398 K). FID sensitivity factors and retention times were determined using ethene ( $99.5 \%$, dried over molsieve) and standard solutions of $\mathbf{1}, \mathbf{2}$, and ethylbenzene (3, 99\%) in methanol (p.a.). The conversion of $\mathbf{2}$ was measured as a function of time [8]. 


\subsection{Liquid-phase hydro-acyloxy-addition of acetic acid (4) to camphene(5)}

A mixture of glacial acetic acid (4 p.a., $0.70 \mathrm{~mol})$, camphene $(595 \%, 0.70 \mathrm{~mol})$ and acetic anhydride (p.a., $9.05 \mathrm{mmol}$ ) was mechanically stirred $(1500 \mathrm{rpm})$ overnight at $328 \mathrm{~K}$ under a $\mathrm{N}_{2}$ atmosphere. Subsequently, $2.5 \mathrm{~g}$ of catalyst was quickly suspended in the reaction mixture. The composition of the soluble fraction of the reaction mixture was analyzed by capillary GC as a function of reaction time; samples were prepared as follows: $1.00 \mathrm{~mL}$ of the reaction mixture was added to water $(25.00 \mathrm{~mL})$ followed by an extraction with $n$-heptane $(25.00 \mathrm{~mL})$. $1.00 \mathrm{~mL}$ of the $n$-heptane fraction was diluted with $n$-heptane to $25.00 \mathrm{~mL}$ in a volumetric flask. $1.0 \mu \mathrm{L}$ of the diluted solution was injected into the GC [Varian 3400, column: DB-5 capillary liquid-phase siloxane polymer (5\% phenyl, $95 \%$ methyl), $30 \mathrm{~m} \times 0.323 \mathrm{~mm}$, temperature program: $5 \mathrm{~min}$ at $333 \mathrm{~K}, 10 \mathrm{~K} / \mathrm{min}$ to $553 \mathrm{~K}, 10 \mathrm{~min}$, carrier gas: $\mathrm{N}_{2}$, FID]. In the case of hydro-acyloxy-addition reactions performed in the presence of water, $320 \mu \mathrm{L}$ (17.78 mmol) $\mathrm{H}_{2} \mathrm{O}$ was added instead of acetic anhydride. To establish whether leaching occurs, the insoluble catalyst particles were removed from the reaction mixture by filtration with a double-ended glass filter under a dry $\mathrm{N}_{2}$ atmosphere (before equilibrium had established), whereas the composition of the reaction mixture was further measured as a function of time. Since no solid residue remained after evaporation of the reaction mixture to dryness in vacuo, removal of the solid particles was complete.

\section{Results and discussion}

\subsection{Catalyst characterization}

The chemical composition of the different catalysts investigated are collected in Table 1. Also the sulfur contents calculated for complete conversion to $\mathrm{Zr}\left(\mathrm{SO}_{4}\right)_{2}$ are indicated. The experimental sulfur contents are lower than the calculated values. The reaction of the silicasupported zirconia with gaseous sulfur trioxide is therefore not complete and the reaction of zirconium hydroxide and zirconia with sulfuric acid involves only a limited fraction of the zirconia. As to be expected, the specific surface area of the catalyst prepared from zirconium hydroxide is much larger than that of the other catalysts. The catalyst based on calcined zirconia exhibited the X-ray diffraction pattern of zirconia and the catalyst based on zirconium hydroxide showed broadened reflection of zirconia. The bulk water-free zirconium sulfate did not display an X-ray diffraction pattern; after exposure to ambient air (relative humidity 50 to $60 \%$ ) for two weeks the sharp X-ray diffraction pattern of $\mathrm{Zr}\left(\mathrm{SO}_{4}\right)_{2} .4 \mathrm{H}_{2} \mathrm{O}$ appeared [1].

Table 1. Quantitative analysis of elements by ICP-AES and Flash-combustion GC for the 10 wt $\% \mathrm{ZrO}_{2} / \mathrm{SiO}_{2}$ subjected to gaseous $\mathrm{SO}_{3}$ and for the conventional $\mathrm{H}_{2} \mathrm{SO}_{4} / \mathrm{ZrO}_{2}$ catalysts. Residual atom (\%): oxygen.

\begin{tabular}{lcccc}
\hline Sample & Element & \multicolumn{2}{c}{ Atom (\%) } & BET area $\left(\mathrm{m}^{2} / \mathrm{g}\right)$ \\
\cline { 2 - 4 } & & $\begin{array}{c}\text { Calc. } \\
(100 \% \text { sulfated })\end{array}$ & $\begin{array}{c}\text { ICP-AES } / \\
\text { Flash-combustion } \mathrm{GC}\end{array}$ & \\
\hline $\mathrm{SO}_{3} / \mathrm{ZrO}_{2} / \mathrm{SiO}_{2}$ & $\mathrm{~S}$ & 3.0 & 1.7 & 50 \\
& $\mathrm{Zr}$ & 1.5 & 1.3 & \\
& $\mathrm{Si}$ & 27.6 & 23.7 & 217 \\
& $\mathrm{~S}$ & 7.3 & 4.0 & 50 \\
\hline $\mathrm{H}_{2} \mathrm{SO}_{4} / \mathrm{ZrO}_{2}$ (prec.) & $\mathrm{Zr}$ & 23.9 & 23.9 & \\
\hline $\mathrm{H}_{2} \mathrm{SO}_{4} / \mathrm{ZrO}_{2}$ (Gimex) & $\mathrm{S}$ & 7.3 & 1.8 & \\
& $\mathrm{Zr}$ & 23.9 & 24.2 & \\
\hline
\end{tabular}

Deposition-precipitation of zirconium hydroxide on silica at a constant $\mathrm{pH}$ level of 4.5 leads to very finely divided zirconia. Fig. 1 shows an electron micrograph of the resulting catalyst precursor. Tiny zirconia particles have been deposited onto the non-porous silica spheres. 


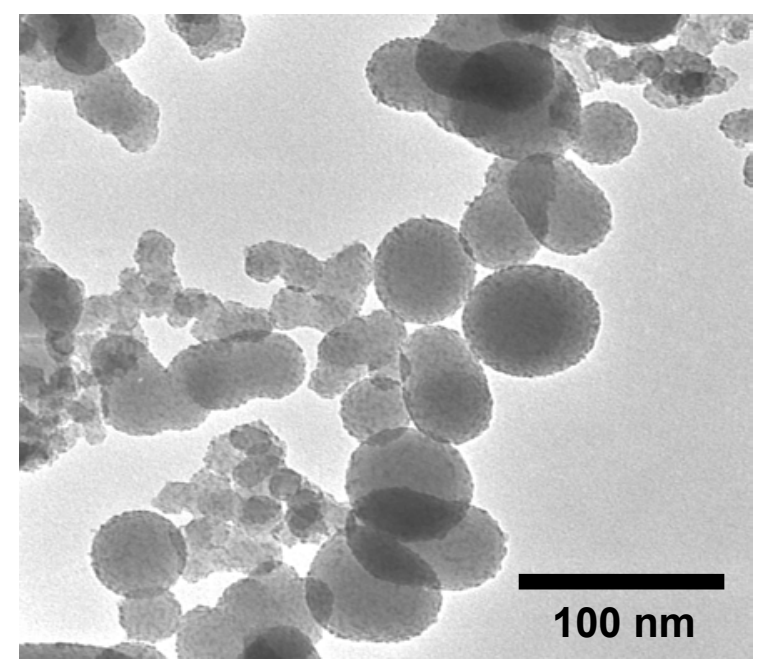

Fig. 1. Transmission electron micrograph of 10 wt. $\% \mathrm{ZrO}_{2} / \mathrm{SiO}_{2}$ prepared by $\mathrm{pH}$ static deposition-precipitation onto silica [8]. Large light-gray spheres: silica support (Aerosil OX50, Degussa-Hüls) Dark dots: zirconia.

Thermogravimetry indicated a continuous weight loss of the sulfated silica supported zirconia of only about $3 \%$. The thermogravimetric data on the catalysts prepared by reaction of zirconia with sulfuric acid were more informative (see also ref. [12]). When the temperature was raised with $10 \mathrm{~K} / \mathrm{min}$, the catalyst prepared by reaction with calcined zirconia showed a much more smooth weight loss, which set on already at about $350 \mathrm{~K}$. Apparently, it is much more difficult to remove the constituents of sulfuric acid out of the much more porous structure of the zirconium hydroxide.

The bulk anhydrous $\mathrm{Zr}\left(\mathrm{SO}_{4}\right)_{2}$ catalyst exhibited a ratio of the areas of the $\mathrm{S}(2 \mathrm{p})$ and the $\operatorname{Zr}\left(3 \mathrm{~d}_{5 / 2,3 / 2}\right)$ peak of 0.50 . Employing XPS atomic sensitivity factors of $S(2 p)=0.54$ and $\operatorname{Zr}\left(3 \mathrm{~d}_{5 / 2,3 / 2}\right)=2.1$, the $\mathrm{S} / \mathrm{Zr}$ atomic ratio is 2.0 , which agrees with the bulk chemical composition. The energy of the $S(2 p)$ peak of the silica-supported zirconia after treatment with sulfur trioxide was at $170.0 \mathrm{eV}$, which agrees nicely with that exhibited by anhydrous bulk zirconium sulfate, which was at $170.3 \mathrm{eV}$ [1]. Bulk anhydrous zirconium sulfate has the $\mathrm{Zr}\left(3 \mathrm{~d}_{5 / 2,3 / 2}\right)$ peak at $185.6 \mathrm{eV}$ and zirconia at $183.3 \mathrm{eV}$. The partial conversion of the supported zirconia into zirconium sulfate is not only evident from the chemical analysis, but also from the energy of the $\operatorname{Zr}\left(3 \mathrm{~d}_{5 / 2,3 / 2}\right)$ peak, which was at $184.1 \mathrm{eV}$. Together with the broadening of the peak, which was $0.3 \mathrm{eV}$, the sulfur-to-zirconium peak ratio being 0.25 instead of 0.5 as measured with the bulk zirconium sulfate, indicates the incomplete reaction of the tiny zirconia particles. It is significant that the zirconia catalysts prepared by reaction of sulfuric acid with zirconium hydroxide exhibit a $\mathrm{S}(2 \mathrm{p})$ binding energy of $169.3 \mathrm{eV}$, which is nearly identical to that of liquid $\mathrm{H}_{2} \mathrm{SO}_{4}\left(169.4 \mathrm{eV}\right.$ [13]). The $\mathrm{Zr}\left(3 \mathrm{~d}_{5 / 2,3 / 2}\right)$ peak of the catalysts is broadened and is positioned at an energy lower than that measured for bulk anhydrous zirconium sulfate. The XPS results therefore point to the presence of sulfuric acid adsorbed on a zirconia surface that has reacted at most to a limited extent to the sulfate.

\subsection{Gas-phase trans-alkylation}

The anhydrous bulk zirconium sulfate preparation did not display any activity in the transalkylation of benzene (1) and diethylbenzene (2) to ethylbenzene (3). At $473 \mathrm{~K}$ the silicasupported, gas-phase sulfated zirconia showed a very small activity, which rapidly dropped to a negligible level (Fig. 2). The conclusion is that Lewis acid sites are not active with sulfated zirconia catalysts. The low activity of the silica-supported catalyst is due to adsorption of some water leading to Brønsted acid sites. Desorption of water at $473 \mathrm{~K}$ leads to the decrease in activity with time. Pre-hydration of the supported catalyst brings about a slightly higher activity as apparent from Fig. 2; the activity drops again due to the loss of water.

Fig. 3 represents the catalytic activity of the two catalysts prepared by reaction with liquid sulfuric acid. The activity has been measured at 473 and at $673 \mathrm{~K}$. In agreement with the result mentioned in ref. [10] that calcined zirconia does not exhibit activity upon reaction with sulfuric acid and calcination, the activity of the $\mathrm{H}_{2} \mathrm{SO}_{4} / \mathrm{ZrO}_{2}($ Gimex) catalyst at $473 \mathrm{~K}$ is low. 
The activity rapidly decreases with time on stream. At $673 \mathrm{~K}$ the catalyst did not show any activity. The catalyst prepared by reaction of precipitated zirconium hydroxide with sulfuric acid and calcination $\left[\mathrm{H}_{2} \mathrm{SO}_{4} / \mathrm{ZrO}_{2}\right.$ (prec.) $]$, on the other hand, exhibited a significantly high conversion, which did not drop with time on stream. At $673 \mathrm{~K}$, however, the latter catalyst also showed a very low activity. Since an activity decreasing with temperature is unusual, we compared the behavior of the sulfated zirconia catalysts with that of an amorphous silicaalumina catalyst.

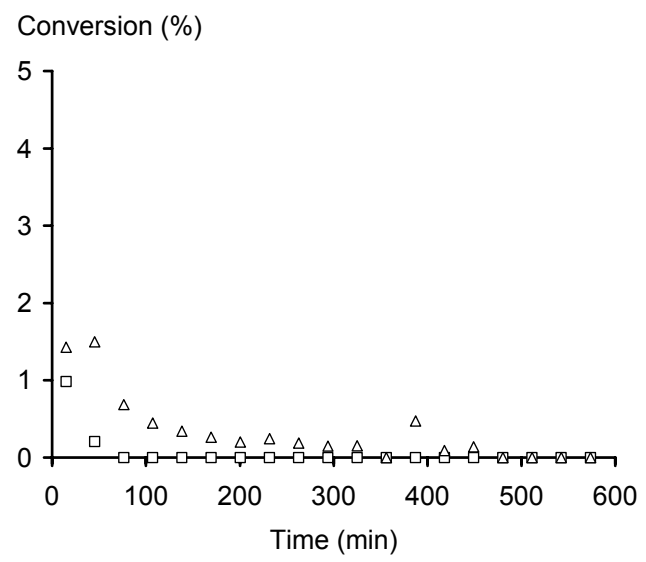

Fig. 2. Conversion of 2 in the transalkylation of benzene (1) and diethylbenzene (2) at $473 \mathrm{~K}$ on $\mathrm{SO}_{3} / \mathrm{ZrO}_{2} / \mathrm{SiO}_{2}$ catalyst; $\square$ before hydration and $\triangle$ after hydration $(2 \mathrm{~h}, 2$ $\left.\% \mathrm{H}_{2} \mathrm{O}, 50 \mathrm{~mL} / \mathrm{min}\right)$.
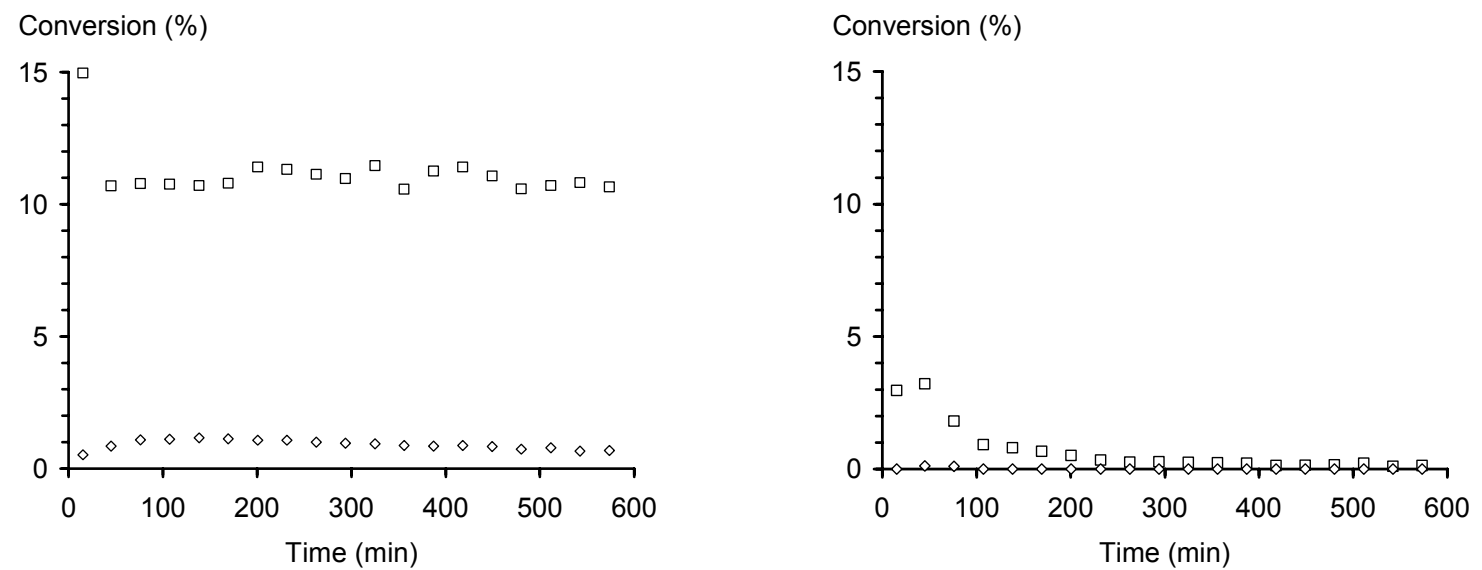

Fig. 3. Conversion of $\mathbf{2}$ in the trans-alkylation of benzene (1) and diethylbenzene (2) on $\mathrm{H}_{2} \mathrm{SO}_{4} / \mathrm{ZrO}_{2}$ (prec.) (left-hand side) and on $\mathrm{H}_{2} \mathrm{SO}_{4} / \mathrm{ZrO}_{2}($ Gimex) (right-hand side) $\square 473 \mathrm{~K}$ and $\diamond 673 \mathrm{~K}$.

Fig. 4 shows the conversion of the silica-alumina catalyst at 473 and $673 \mathrm{~K}$. Fig. 4 also indicates that the amorphous silica-alumina catalyst displays the expected dependence of the temperature; at higher temperature the conversion is higher. The higher activity is partly due to reaction to ethene; at $473 \mathrm{~K}$ the selectivity to ethylbenzene (3) is $100 \%$, but $50 \%$ at $673 \mathrm{~K}$.

The anomalous behavior of the sulfated zirconia catalysts is due to the loss of sulfuric acid at elevated temperatures. The catalyst prepared from calcined zirconia looses its sulfuric acid at $673 \mathrm{~K}$ and, consequently, is not active at this temperature. As a result, decreasing the temperature of the catalyst to $473 \mathrm{~K}$ does not restore the activity. Also the more highly porous catalyst prepared from zirconium hydroxide releases sulfuric acid, but in narrow pores some sulfuric acid is left. The loss of sulfuric acid at $673 \mathrm{~K}$ is obviously irreversible. When the catalyst prepared from zirconium hydroxide is, however, kept at $473 \mathrm{~K}$, the transport of water out of the porous structure is thus low that a stable activity is exhibited. Pre-hydration of the bulk anhydrous zirconium sulfate does not provide an active catalyst. That no catalytic activity is induced in this case is due to the fact that bulk anhydrous zirconium sulfate readily reacts to a stable tetrahydrate, viz., $\mathrm{Zr}\left(\mathrm{SO}_{4}\right)_{2} \cdot 4 \mathrm{H}_{2} \mathrm{O}$ [1]. As a result the hydrolysis of the sulfate by water vapor is suppressed. 


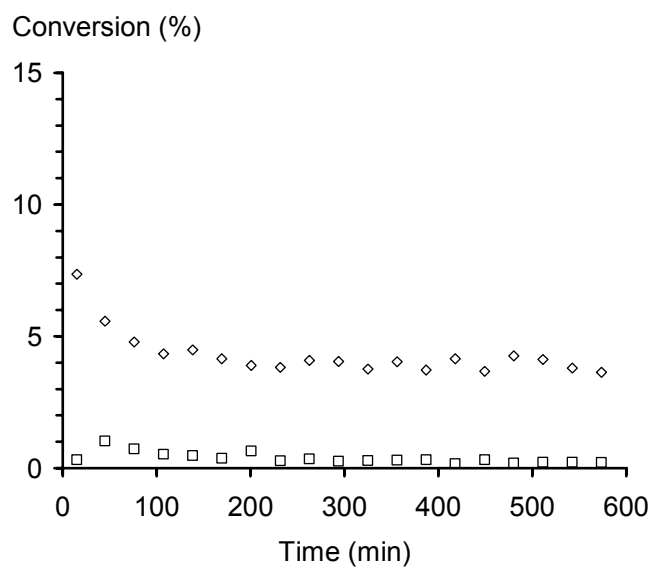

Fig. 4. Conversion of 2 in the transalkylation of benzene (1) and diethylbenzene (2) on amorphous silicaalumina. $\square 473 \mathrm{~K}$ and $\diamond 673 \mathrm{~K}$.

\subsection{Liquid-phase hydro-acyloxy addition}

Neither the anhydrous bulk zirconium sulfate nor the silica-supported, sulfated zirconia were active in the addition of acetic acid (4) to camphene (5). The lack of activity is due to the fact that addition of acetic anhydride removes water completely from the reactants. Also the liquid-phase reaction thus demonstrates that Lewis acid sites are not active in our catalysts. Addition of water leads to a well measurable activity with both catalysts. Fig. 5 represents the activity of the silica-supported sulfated catalyst after pre-hydration. The activity is considerable, but a homogeneous catalyst, such as, sulfuric acid or $\mathrm{BF}_{3}$ in acetic acid, is more active raising the conversion to about $70 \%$ in $1500 \mathrm{~min}$. It is interesting that filtration of the catalyst did not stop the reaction. Apparently some sulfuric acid has been formed by reaction with the water, which has been released by the catalyst into the solution.

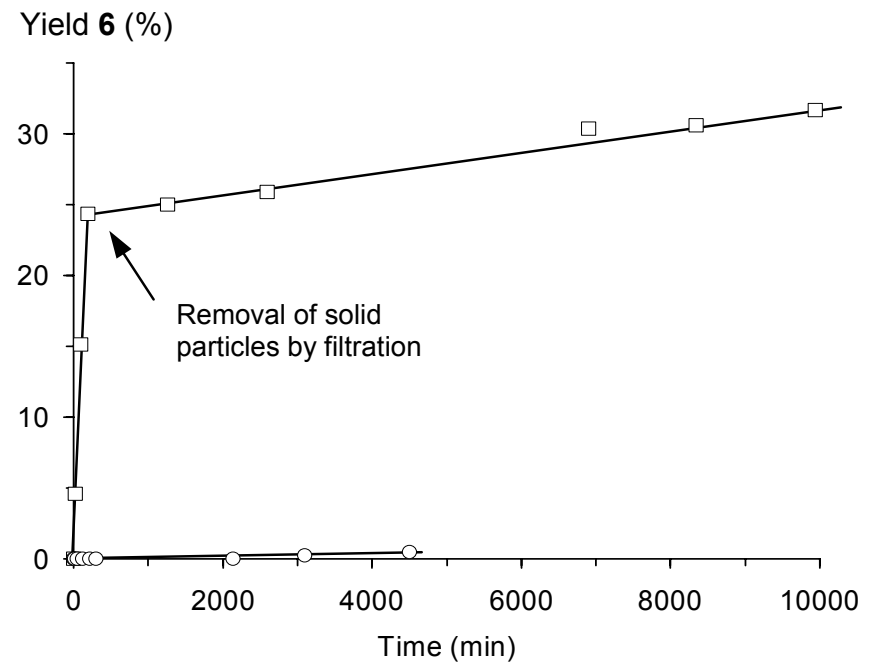

Fig. 5. Course of the reaction to isobornyl acetate (6) by the hydro-acyloxy-addition of 0.70 mol acetic acid (4) to $0.70 \mathrm{~mol}$ camphene (5) at $338 \mathrm{~K}$ (stirred tank reactor, $\mathrm{N}_{2}$ atmosphere). ○ $2.5 \mathrm{~g} \mathrm{SO}_{3} / \mathrm{ZrO}_{2} / \mathrm{SiO}_{2}$ without $\mathrm{H}_{2} \mathrm{O}$ and $\square 2.5 \mathrm{~g} \mathrm{SO}_{3} / \mathrm{ZrO}_{2} / \mathrm{SiO}_{2}$ and $320 \mathrm{ml}(17.78 \mathrm{mmol})$ $\mathrm{H}_{2} \mathrm{O}$.

Fig. 6 shows the activities of the sulfated zirconium hydroxide and the sulfated calcined zirconia catalyst. In contrast to the activities displayed in the gas-phase reaction, the calcined zirconia catalyst now shows the higher activity. Since the mass transport in the liquid is much slower, the rate of the reaction is now more strongly transport-limited with the catalyst prepared from the more porous zirconium hydroxide. Upon removal of the solid catalyst by filtration the reaction continues also with these two catalysts. 


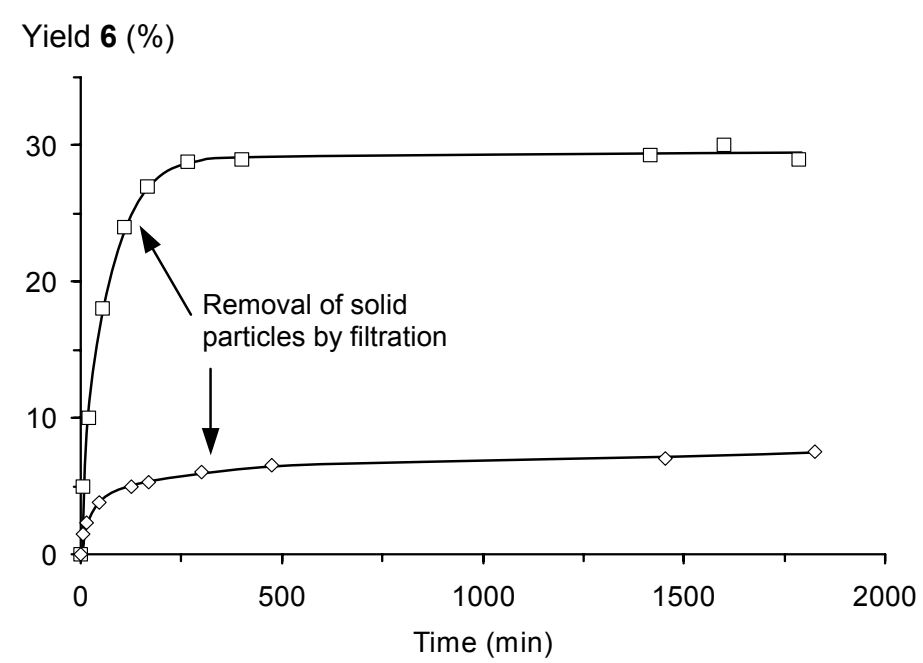

Fig. 6. Course of the reaction to isobornyl acetate (6) by the hydro-acyloxy-addition of 0.70 mol glacial acetic acid (4) to 0.70 mol camphene (5) at $338 \mathrm{~K}$ (stirred tank reactor, $\mathrm{N}_{2}$ atmosphere). $\square \quad 2.5 \mathrm{~g}$ $\mathrm{H}_{2} \mathrm{SO}_{4} / \mathrm{ZrO}_{2}($ Gimex) and $\diamond$ $2.5 \mathrm{~g} \mathrm{H}_{2} \mathrm{SO}_{4} / \mathrm{ZrO}_{2}$ (prec.).

\section{Conclusions}

The sulfated zirconia catalysts prepared and investigated in this research do not exhibit activity due to Lewis acid sites both in a gas-phase and in a liquid-phase reaction. The positive effect of water as well as the XPS evidence together with infrared results from the literature suggests that sulfated zirconia catalysts are actually zirconia-supported sulfuric acid catalysts.

The fact that sulfuric acid is the active component leads to a drawback of sulfated zirconia catalysts. In gas-phase reactions at temperatures where the vapor pressure of the constituents of sulfuric acid is considerable, de-activation of the catalyst has to be taken into account. A highly porous structure can significantly slow down the loss of the active constituent of the catalysts. In the liquid-phase dissolution of sulfuric acid can lead to corrosive properties and to contamination of the reaction products. Furthermore deactivation of the catalyst will eventually result.

\section{References}

[1] I.J. Dijs, R. de Koning, J.W. Geus, L.W. Jenneskens, Phys. Chem. Chem. Phys. 3 (2001) 4423.

[2] K. Tanabe, M. Misono, Y. Ono, H. Hattori, New Solid Acids and Bases, Their Catalytic Properties, Elsevier, Amsterdam, 1989.

[3] G.D. Yadav, J.J. Nair, Microporous Mesoporous Mater. 33 (1999) 1.

[4] X. Song, A. Sayari, Catal. Rev.-Sci. Eng. 38 (1996) 329.

[5] F. Babou, B. Bigot, G. Coudurier, P. Sautet, J.C. Védrine, Stud. Surf. Sci. Catal. 90 (1994) 519.

[6] K. Arata, M. Hino, Mater. Chem. Phys. 26 (1990) 213.

[7] A. Corma, A. Martínez, C. Martínez, Appl. Catal. A. 144 (1996) 249.

[8] I.J. Dijs, J.W. Geus, L.W. Jenneskens, J. Phys. Chem. B. submitted for publication.

[9] T.-C. Tsai, S.-B. Liu, I. Wang, Appl. Catal. A. 181 (1999) 355.

[10] J.O. Bledsoe, Terpenoids, in: J.I. Kroschwitz, M. Howe-Grant (Eds.), Kirk-Othmer Encyclopedia of Chemical Technology, 4th Edition, Wiley, New York, 1997, Vol. 23, pp. 833-882.

[11] F.R. Chen, G. Coudurier, J.-F. Joly, J.C. Vedrine, J. Catal. 143 (1993) 616.

[12] S. Ardizzone, C.L. Bianchi, E. Grassi, Coll. Surf. A. 135 (1998) 41.

[13] D.H. Fairbrother, H. Johnston, G. Samorjai, J. Phys. Chem. 100 (1996) 13696. 